\title{
Fusion researchers face fight for funds
}

Weapons lobby

\section{will oppose Reagan's cuts}

\section{Washington}

Research into inertial confinement fusion (ICF) - the use of lasers or particle beams to ignite pellets of tritium and deuterium - is fighting for its political life. Supporters in Congress are trying to head off a direct frontal attack by the Reagan Administration, which wants to reduce the ICF operating budget by 25 per cent next year. And already it seems virtually certain that funds will dry up for what some see as the most technically-promising way of obtaining usable energy from such fusion reactions, the use of heavy ion beam drives.

ICF research has been a constant battleground for several years. At present the research is funded as a defence-related programme within the Department of Energy, since the explosion of the pellets can be used to study the simulated effects of nuclear weapons. The Armed Services Commitee in the House of Representatives has been a particularly enthusiastic supporter, championing the construction of facilities at the Department of Energy's two weapons research laboratories and the Sandia Laboratories in Albuquerque, New Mexico, at a total cost of more that $\$ 1,000$ million since 1977 .

However, scepticism within the Office of Management and Budget over whether this level of expenditure is justified has recently been fanned by several factors. One is the continuing difficulty being experienced by the laboratories in approaching the point of thermonuclear ignition, and another is the extreme tight-fistedness of the new Administration, seeking in particular to find ways of reducing federal support for applied energy research.

Things were already turning sour before $\mathrm{Mr}$ Reagan came into office. When $\mathrm{Mr}$ Carter presented his budget for 1982 to Congress in January, he proposed a total of $\$ 219$ million to support ICF, the same level of funding as last year with no increase to allow for inflation, and considerably less than the Department of Energy had requested. The Reagan Administration reduced this still further to $\$ 180$ million. In particular, it suggested that operating funds for the ICF programme be reduced from Mr Carter's proposed \$140 million to $\$ 106$ million, a figure which could result in the lay-off of 300 to 400 scientific and technical staff according to the director of the Office of Inertial Fusion, Dr Richard L. Schriever.

These budget reductions are being sharply contested by the House Armed Services

Committee, which is responsible for overseeing the ICF programme. The committee voted to restore all of the money which the Reagan Administration wants to cut, increasing the department's request for operating funds from $\$ 106$ to $\$ 156$ million. This represents the single largest increase recommended in the weapons research budget, and was accepted by the full House of Representatives when it voted on the authorizing bill last week. It now passes to the Senate, and then on to the appropriations committees, where it could get a rougher ride.

The Office of Management and Budget is unlikely to give up the fight. There are rumours of demands for even bigger cuts in the ICF budget for 1983. In particular,

\section{Fredrickson quits without warning}

\section{Washington}

To the consternation of the US biomedical research community, $\mathrm{Dr}$ Donald Fredrickson announced unexpectedly last Friday that he will be leaving his position as director of the National Institutes of Health (NIH) on 1 July.

Dr Fredrickson cites "personal" reasons for leaving the world's largest biomedical research organization, referring in particular to the weight of administrative responsibilities and a desire to return to his research in lipoproteins and lipid transport. He has denied any differences of opinion with the new Administration over the funding of biomedical research, although the speed of his departure has inevitably provoked rumours of problems which have yet to surface publicly.

One point of particular frustration to $\mathrm{Dr}$ Fredrickson is said to have been the difficulty of making appointments to top positions at NIH at a time when any such decision requires a special exemption from the current freeze in federal hiring. Several senior administrators have recently left NIH, including Dr Robert L. Goldberger, deputy director for science, who has been appointed provost and vice-president for health sciences at Columbia University in New York.

A respected scientist and a popular administrator, Dr Fredrickson first joined NIH 28 years ago, and was appointed their director by President Gerald Ford in 1975. $\mathrm{He}$ had previously been director of the National Heart and Lung Institute, and in 1974 became president of the Institute of Medicine at the National Academy of Sciences.

Dr Fredrickson is said to have a good working relationship with the new Secretary of Health and Human Services, Mr Richard Schweiker. Mr Schweiker had previously been a keen supporter of NIH as a member of the Senate's Human Resources Committee, and is said to have recently agreed to reconfirm $\mathrm{Dr}$ Fredrickson's appointment - just as $\mathrm{Mr}$ officials are keeping up their efforts to quash plans supported by the Armed Services Committee to upgrade the NOVA glass laser facility under construction at the University of California's Lawrence Livermore Laboratory.

Scientists at Livermore strongly refute charges that NOVA represents unnecessarily extravagant expenditure. They point to recent research results which have raised hopes that thermonuclear ignition can be reached on schedule by 1986-87. In particular last year's discovery that much higher efficiencies in beam-target coupling can be achieved using shorter wavelength light. This is already being used as the basis for a planned experiment, using two of

Joseph Califano had done when Mr Carter became president in 1977

If $\mathrm{Dr}$ Fredrickson is having problems with other members of the new Administration, then they are being well concealed. The conviction that there must be some unexplained reasons for his rapid departure seems partly an expression of disappointment that a popular director is leaving NIH in the hands of an unknown

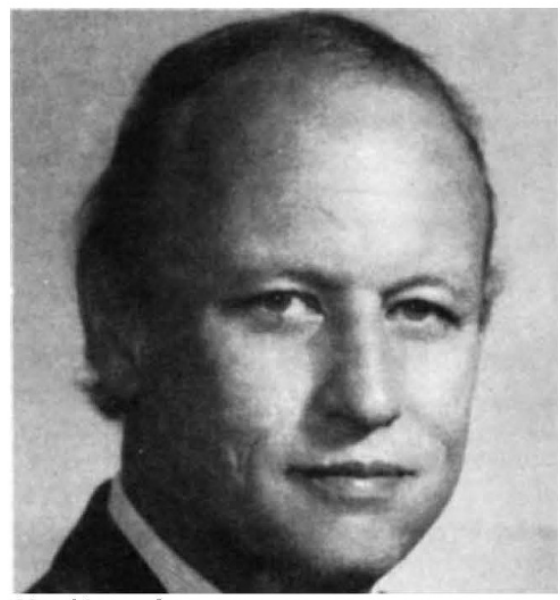

No whisper where next

successor just when possible budget restrictions could mean a new period of uncertainty. During Dr Fredrickson's tenure at NIH the research budget has increased from $\$ 1,880$ to about $\$ 3,500$ million, although the rate of expansion has lately slowed considerably.

Last week, in delivering an emotional address to NIH staff at the end of which he announced that he had submitted his resignation to President Reagan, Dr Fredrickson said that NIH were "healthy, strong and in the prime of life", while warning that the essence of the institutes' greatness was "fragile and could be destroyed by careless trustees". He has made no announcement about future plans, apart from telling senior staff that he will spend some months with the National Academy of Sciences.

David Dickson 